Sharif University of Technology
Scientia Iranica
SCIENTIA
I RAN I C A
http://scientiairanica.sharif.edu

\title{
SCF distribution in FRP-strengthened tubular T-joints under brace axial loading
}

\author{
A. Sadat Hosseini ${ }^{\mathrm{a}}$, M.R. Bahaari ${ }^{\mathrm{a}, *}$, and M. Lesani ${ }^{\mathrm{b}}$ \\ a. School of Civil Engineering, College of Engineering, University of Tehran, Tehran, P.O. Box 11155-4563, Iran. \\ b. School of Civil Engineering, College of Engineering, Sadra University, Tehran, P.O. Box 314-14875, Iran. \\ Received 30 November 2017; received in revised form 6 January 2018; accepted 29 April 2018
}

\author{
KEYWORDS \\ Tubular T-joint; \\ FRP; \\ Strengthening; \\ $\mathrm{SCF}$; \\ Finite Elements (FE).
}

\begin{abstract}
The present article is dedicated to the study of the effects of different parameters of Fiber-Reinforced Polymers (FRP), as strengthening material, on a tubular Tjoint subjected to brace axial loading using Finite Element (FE) analyses. The effectiveness of FRP materials in enhancing the fatigue life of tubular T-joints was investigated through computing the ratio of the Stress Concentration Factors (SCFs). FRP parameters considered here include fiber orientation, FRP thickness, effective wrapping length, and FRP material properties. The FRP materials were modeled and applied to a basic numerical FE model, which was validated in the past against well-known experimental results on weld-toe SCFs. Promising results were derived from the analyses, showing that the FRP strengthening method can effectively decrease the SCF values for tubular T-joints.
\end{abstract}

(C) 2020 Sharif University of Technology. All rights reserved.

\section{Introduction}

Adequate structural performance of steel Circular Hollow Sections (CHS) against buckling, bending, and torsion has made them the best choice for designers of offshore structures. In addition, high strength-toweight ratio, high buoyancy, and lower drag coefficients are known as another vantages [1]. Offshore CHSs are usually connected to form joints using the butt-welding technique. The most common and basic CHS joint configuration is the $\mathrm{T}$-joint, which is made by welding the cross-section of one tube (brace) perpendicular to the undisturbed exterior surface of the other tube (chord).

Numerical studies on tubular joints using the

\footnotetext{
*. Corresponding author. Tel.: +982144748551

Fax: +982144748545

E-mail addresses: a.sadat@ut.ac.ir (A. Sadat Hosseini); mbahari@ut.ac.ir (M.R.Bahaari); m.lesani@sadra.ac.ir (M. Lesani)
}

doi: $10.24200 /$ sci. 2018.5471 .1293
Finite Element (FE) method have been done for more than two decades. For instance, Lee [2] reviewed the modeling techniques used in the FE analysis of tubular joints for obtaining information on strength, stress fields, and stress intensity factors. In this study, guidance is given to model discretization, i.e., choice of elements, material curve input, weld modeling, interpretation of results, and limitations of using numerical techniques. In lieu of these studies, a comprehensive FE study of Fiber-Reinforced Polymer (FRP) parameters of FRP strengthened tubular T-joints is carried out.

Fatigue damage in offshore steel jacket structures is of crucial attention due to the cyclic nature of wave loading on such structures. Thus, the prediction of fatigue life of offshore structural joints and accurate fatigue load resistance are necessary to ensure structural safety. A novel example of fatigue life assessment studies is the structural stress approach presented [3]. They improved the zero point structural stress approach to calculating the structural stress for the fatigue life assessment of tubular joints.

Fatigue life of offshore structures is normally 
assessed using Stress-Life (S-N) curves. In this way, the Hot-Spot Stress Range (HSSR) is calculated from a parameter called the Stress Concentration Factor (SCF). According to API ([4], Part 8.3.1), "For each tubular joint configuration and each type of brace loading, $\mathrm{SCF}$ is defined as: $\mathrm{SCF}=$ The HSSR/nominal brace stress fi". Here, this research is aimed at the estimation of SCFs at the chord. Therefore, the HSSR is the hot spot stress range on the chord, which must be divided by the nominal direct stress in the brace member to attain the SCF. Having the HSSR and using $\mathrm{S}-\mathrm{N}$ curves, the number of loading cycles that the structure can sustain before failure could be estimated.

Offshore structural members are subjected to different kinds of loadings, such as axial load, In-Plane Bending (IPB), and Out-of-Plane Bending (OPB) along with their combination, so-called as multi-axial loading. API [4] presented a conventional method to determine the HSS. In this method, extrapolated geometric stress at the weld toe is to sum the products of the nominal stresses due to each load type and the corresponding SCFs.

SCFs can be considered in unstiffened and stiffened joints. In unstiffened joints, researchers have put in many efforts since 1970s, and their main objective has been concerned with deriving parametric equations for the SCF calculation. More papers relevant to the present study are reviewed hereunder.

Kuang et al. [5] presented parametric equations for the estimation of SCF in T-, Y-, K-, and KTjoints using shell elements in a FE program. Despite the fact that these equations were presented four decades ago, they are still widely used in the fatigue design of offshore tubular joints. Wordsworth and Smedley [6] presented equations for the SCF estimation in $\mathrm{T}-$, $\mathrm{Y}-$, and $\mathrm{X}$-joints under axial force, IPB and OPB moments. A complete set of SCF equations for T-, Y-, and K-joints was presented by Efthymiou and Durkin [7]. Hellier et al. [8] presented semiempirical equations for the SCF calculation in tubular $\mathrm{Y}$ - and T-joints. They performed FE analyses that covered a wide range of joint geometries under axial loading, IPB, and OPB. Ramachandra Murthy et al. [9] studied the effect of geometric parameters on SCFs in ring stiffened $\mathrm{T}$ - and $\mathrm{Y}$-joints and presented relevant formulae. Nwosu et al. [10] studied the stress distribution along the ring stiffened T-joints. In this research, the effects of geometry, location, and number of stiffeners were studied. Parametric equations were presented by Lloyd's Register (LR) [11], which were derived from fitting curves in the existing SCF database. These equations address the SCFs in saddle and crown positions in T-, Y-, X-, K-, and KTjoints and are now considered as one of the most liable references for the SCF estimation. Morgan and Lee [12] presented a set of equations for the SCF estimation in K-joints using FEs analysis. Parametric equations were presented to estimate the stress distribution along the chord-brace intersection for T-, Y-, X-, and KTjoints $[13,14]$. Karamanos et al. [15] investigated the SCFs of multiplanar welded tubular XX-joints under various loading conditions such as axial brace load, inplane and OPB, and axial and bending chord loads using FE analysis. They presented the SCF results in the form of parametric equations and diagrams. A comprehensive numerical study of stress concentrations in welded tubular steel gap K-joints was carried out by Karamanos et al. [16]. Design guidance in the form of graphs and equations for the reliable determination of SCFs was proposed to be used for the fatigue design of welded tubular K-connections. Wingerde et al. [17] proposed a set of equations and diagrams to estimate the SCFs in uni-planar K and multi-planar KK-joints. SCF distributions along the intersections of a T-joint reinforced with a doubler plate subjected to combined loadings were investigated by Hoon et al. [18]. Myers et al. [19] investigated the effect of three kinds of longitudinal stiffeners in the chord member on SCFs in jack-up platforms. SCF equations in multi-planar welded tubular DT-joints were presented by Karamanos et al. [20]. Gao et al. [21-23] presented the SCF formulae for fully overlapped K(N)-joints. Shao [24] investigated the SCFs along the weld of the tubular K-joints subjected to IPB load through experiments and numerical analysis. Woghiren and Brennan [25] presented a set of SCF equations for multi-planar KK-joints, which were stiffened by the rack plate. Lotfollahi-Yaghin and Ahmadi [26] and Ahmadi et al. [27] proposed equations to predict the SCF along the weld toe of uni-planar KT- and DKT-joints under axial loading. Ahmadi et al. [28] investigated the effect of SCFs on the structural integrity assessment of multiplanar offshore tubular DKT-joints. They proposed a fatigue limit-state function based on the fracture mechanics and investigated its effects on the results of reliability analysis of assigning different values to deterministic variables involved in this limit-state function. Lotfollahi-Yaghin and Ahmadi [29] and Ahmadi et al. [30] presented SCF distribution parametric equations along the weld toe of outer-inclined and centralvertical braces of two-planar DKT-joints. Fatigue design equations for internal ring-stiffened KT-joints under axial loading were proposed [31,32]. Ahmadi and Lotfollahi-Yaghin [33] performed a set of geometrically parametric FE stress analyses for right-angle three planar tubular KT-joints under three different axial loading conditions. A new set of SCF design equations was established for the fatigue design of three-planar KTjoints through nonlinear regression analysis. Ahmadi et al. [34] carried out a set of parametric SCF analyses for right-angle three-planar tubular KT-joints under three different axial loading conditions. In this study, 
the effect of geometrical characteristics and loading conditions on the SCFs at different saddle positions on the main (outer) braces was investigated. Ahmadi and Lotfollahi-Yaghin [35] carried out a FE analysis of multi-planar tubular DKT-joints and proposed a probability distribution model for SCFs along the weld toe of the central brace under axial loads. Ahmadi and Lotfollahi-Yaghin [36] proposed a fatigue limit-state function for multi-planar tubular DKT-joints using the principles of the S-N-based fatigue strength assessment. They also investigated the effects of different variable characteristics on the results of reliability analysis. Yang et al. [37] investigated the SCFs of negative large eccentricity tubular $\mathrm{N}$-joints under axial compressive loading in vertical brace through experiments and numerical analysis. Moreover, a set of parametric equations was proposed in order to calculate the SCFs of negative large eccentricity tubular N-joints. The study of stress concentration in KT-joints of offshore platforms under OPB moments was performed by Ahmadi and Zavvar [38], and the parametric equations were presented.

As previously mentioned, there are some metallicbased methods used for strengthening the CHS-joints. A part of the most recent literature on metallicbased strengthening methods is presented as follows. Nassiraei et al. [39] investigated the static strength of steel tubular $\mathrm{T} / \mathrm{Y}$-joints reinforced with a collar plate under axially compressive loads. They found that the ultimate strength of a collar plate reinforced $\mathrm{T} / \mathrm{Y}$-joint could increase up to $170 \%$ of the strength of the corresponding unreinforced joint. The parametric study was performed, and a new equation for determining the ultimate strength through nonlinear regression analysis was proposed. Nassiraei et al. [40] numerically studied the static strength of CHS T/Yjoints reinforced with collar plates subjected to axial tension load. Through the analysis, the effects of joint geometry and collar plate size on the ultimate strength, failure mechanisms, and initial stiffness via a parametric study were investigated. Finally, a parametric formula for the estimation of ultimate strength of the static design of collar plate reinforced $\mathrm{T} / \mathrm{Y}$-joints under brace tension was presented. Nassiraei et al. [41] studied the static strength of collar plate reinforced tubular T/Y-joints subjected to IPB moment through FE analysis to evaluate the effect of joint geometry and collar plate size on the ultimate strength and failure modes. The results of their analysis showed that the collar plate reinforcement method could significantly increase the ultimate strength and improve the failure mechanisms of tubular $\mathrm{T} / \mathrm{Y}$-joints under IPB load. The parametric study was performed, and a new formula was proposed through nonlinear regression analysis. Nassiraei et al. [42] numerically investigated the ultimate strength, initial stiffness, and failure mechanisms of doubler plate reinforced tubular $\mathrm{T} / \mathrm{Y}$-joints under axial compressive load and derived a new formula from a parametric study. They found that this method could increase initial stiffness and improve the failure modes. In addition, doubler plate reinforcement could enhance the ultimate strength of the T/Y-joints up to $195 \%$. Numerical analysis was used to investigate the geometrical effect on the ultimate strength, initial stiffness, and failure modes in the doubler plate reinforced tubular $\mathrm{T} / \mathrm{Y}$-joints under axial tensile load by Nassiraei et al. [43]. Their study indicated that the doubler plate could significantly increase the initial stiffness and ultimate capacity and, thus, improve failure modes considerably. Geometric parameters were studied, and an ultimate capacity parametric formula for the static analyses of doubler plate reinforced tubular $\mathrm{T} / \mathrm{Y}$-joints under axial tensile load was presented. Nassiraei et al. [44] numerically investigated the effect of the doubler plate size and joint geometry on the static strength of the doubler plate strengthened tubular $\mathrm{T} / \mathrm{Y}$-joints subjected to IPB. This study showed that the doubler plate could significantly enhance the initial stiffness and ultimate capacity and, also, improve failure patterns considerably. They also presented the ultimate capacity parametric formula as a result of the geometrically parametric study. The static capacity of circular hollow section X-joints, strengthened with collar plates, under brace compression was experimentally and numerically investigated by Nassiraei et al. [45]. They observed that the collar plate could increase both of the initial stiffness and ultimate strength of the X-joints. Some researchers specifically carried out studies on the SCF parameter in CHSs. Shao [46] studied the effect of collar-plate reinforcement on the static strength of tubular T-joints under axial loading through experimental test and FE simulation. Based on the parametric study, it was found that the static strength could be greatly improved by increasing the collarplate thickness to chord wall thickness ratio and the collar-plate length to brace diameter ratio. Parametric equations were also developed in this study. Ahmadi et al. [47] performed experiments and numerical analysis and proposed probability distribution models for SCFs in internally ring-stiffened tubular KT-joints subjected to axial loads. A parametric study was carried out and, correspondingly, density histograms were generated for a set of sample data bases for the maximum centraland outer-brace SCFs. Probability density functions for the probabilistic analysis of SCFs in tubular KTjoints reinforced with internal ring stiffeners under IPB moments were presented by Ahmadi et al. [48] based on a FE parametric study. Ahmadi [49] developed a probability distribution model for the SCFs in tubular KT-joints reinforced with internal ring stiffeners subjected to four types of OPB loads. 
In addition to metallic-based strengthening methods, non-metallic strengthening methods have been investigated. For instance, Xu et al. [50] experimentally investigated the SCFs of thin-walled circular hollow section T-, Y-, K-, and KT-joints filled with selfcompacting concrete subjected to axial tension loading. Chen et al. [51] investigated the SCFs of concretefilled circular chord and square braces in K-joints under balanced axial loading both experimentally and numerically. They observed that the SCFs of concrete-filled circular chord and square braces K-joints were lower than those of the corresponding hollow circular chord and square brace K-joints. SCFs in concrete-filled tubular Y-joints subject to IPB were experimentally investigated by Yang et al. [52]. This strengthening method effectively reduced the SCF value. Moreover, SCF is evenly distributed when the value of the axial compression ratio in the chord is increased. Jiang et al. [53] performed experimental tests on tubular Tjoints reinforced with the grouted sleeve to investigate their mechanical behavior. They discussed the failure mode, ultimate load, initial stiffness, and deformability of these joint specimens. It was found that the grouted sleeve provided strength enhancement up to $154.3 \% \sim 172.7 \%$ of the corresponding un-reinforced joint.

In this category, external reinforcement schemes, such as FRP-based strengthening techniques, are the alternatives. FRP wrapping method due to its convenience of handling and application, corrosion resistance, potentially high overall durability, light weight, superior strength-to-weight ratio, tailorability, and high specific performance attributes could be easier for its application in areas whose conventional materials may encounter durability, weight, and/or lack of design flexibility constraints. FRP is usually applied as the strengthening material to the structures in which one or a few existing members could not bear the existing design or service loads. This may result from a probable inaccurate design, recent strict changes in design codes, or implementation restrictions concerning the use of stronger members.

Among a number of studies on FRP strengthened steel structures, the research studies done by Hollaway and Cadei [54], Zhao and Zhang [55], and Zhao [56] are remarkable. There are many external strengthening methods for enhancing the mechanical properties of steel members. FRP-strengthened CHSs with four layers of Carbon Fiber Reinforced Polymer (CFRP) under tension loading were investigated by Jiao and Zhao [57]. Shaat and Fam [58] experimentally investigated steel short columns strengthened with CFRP. Zhao et al. [59] studied the load-bearing capacity of RHSs strengthened with CFRP sheets. Bambach et al. [60] investigated the cross-ply FRP strengthening of thin walled steel sections. Wang et al. [61] investigated the restraining effect of using external glass FRP composites in steel tubes subjected to significant axial displacement. Nishino and Furukawa [62] studied the buckling behavior of externally reinforced steel tubes with CFRP. According to this study, the amount of CFRP used as a strengthening component had an important role in avoiding buckling and, subsequently, increasing the section capacity. Teng and $\mathrm{Hu}$ [63] investigated the influence of wrapping techniques on the deformation capacity of steel tubes under static axial loading. Alemdar et al. [64] experimentally and analytically investigated the fatigue performance of cover-plate specimens with CFRP reinforced welded connections. Lesani et al. [65] numerically investigated the failure pattern, ultimate static strength, and detailed behavior of steel tubular T-joints strengthened by GFRP (glass/epoxy) under axial brace compressive loading. A remarkable increase in the ultimate joint capacity due to the combined action of steel and composite against the compressive load was observed. In addition, critical deformations and ovalization of chord member showed a descending trend up to $50 \%$ of the un-strengthened joint. Lesani et al. [66] experimentally investigated the improvement of the ultimate capacity of T-joints wrapped with GFRP (glass/vinyl ester) under static compressive loading. An increase up to $50 \%$ in the ultimate load-bearing capacity of the tubular joint strengthened by FRP was observed. Further, a detailed survey of failure modes in the composite plies was performed. A numerical and experimental research program was conducted by Lesani et al. [67] on T- and Y-shaped CHS steel tubular connections strengthened with GFRP. In this research, the state of joint strength, deformation, ovalization, stresses, and failure of $\mathrm{T}$ - and $\mathrm{Y}$-joints under compressive loading were investigated. This research showed that the static strength of tubular joints could be improved significantly by the FRP wrapping technique. Based on the improvements observed in the static strength, the investigation of SCF improvement and fatigue strength enhancement using the FRP wrapping technique was deemed necessary.

Obviously, a considerable effort has been devoted to studying SCFs in various unstiffened joints, yet not as much to stiffened joints during the past years. In all of these stiffened joints, metallic-based schemes were used as the strengthening technique. Numerous advantages of non-metallic schemes, such as the FRPwrapping technique, in enhancing the static loadbearing capacity of CHSs along with the increasing interest in using such reinforcing schemes substantiated this study to investigate the SCFs in FRP-strengthened joints to confirm the efficacy of this option. The present research has focused on investigations not addressed in previously published literature. In this paper, the results of numerical analyses of 58 FRP-strengthened 
steel tubular T-joints were used to present the effect of FRP wrapping parameters including fiber orientation, layup thickness, strengthening length, and FRP material type on the SCF distribution along the weld toe under brace axial load. The FE models were verified against the experimental results [11] and the predictions of Lloyd's Register (LR) [11] and API [4] equations. The FE models cover the most substantial FRP wrapping parameters, which could be helpful in the fatigue design of FRP strengthened T-joints under brace axial load.

\section{FE modeling and analysis}

Due to the complexity associated with the geometry of tubular joints, it is difficult to use closed-form solutions for capturing the relative strains and stresses. The FE method verified with experimental investigations is among the reliable alternatives. In this study, a FE model has been developed, and a relative linear elastic numerical analysis has been carried out using ABAQUS [68] software package. The geometry of the unstiffened joint was chosen from the experimental models [11]. The geometric parameters of the joint are presented in Table 1.

Details of the numerical modeling and analysis are presented in the following subsections.

\subsection{Characteristics of analyzed models}

To study the distribution of SCFs along the weld toe in FRP-strengthened tubular T-joints, $58 \mathrm{FE}$ models were generated and analyzed. All of the joints are of un-stiffened geometry, which was chosen from elastic stress concentration factor tests on tubular steel jointsJISSP project [11], with different FRP layups. They were subjected to axial load exerted on top of the brace member. The aim of this study is to investigate the effect of FRP parameters on the stress distribution along the weld toe. The parametric studies were carried out on three different layup configurations related to the chord, brace, and the connection zone (chord and brace intersection). These models investigate the effects of fiber orientation orientation of FRP layup $\left(0^{\circ}, \pm 30^{\circ}, \pm 45^{\circ}, \pm 60^{\circ}\right.$, and $90^{\circ}$ ply angles $)$, FRP layup thickness ( 0.08 to 0.80 times the member thickness), length of FRP reinforcement ( 0.25 to 1.5 times the chord diameter and 2 times the brace diameter), and different types of FRP material including

Table 1. The geometric parameters of the T-joint.

\begin{tabular}{lccccc}
\hline Reference & $\boldsymbol{D}(\mathbf{m m})$ & $\boldsymbol{\alpha}$ & $\boldsymbol{\beta}$ & $\boldsymbol{\gamma}$ & $\boldsymbol{\tau}$ \\
\hline JISSP1.3 & 508 & 10 & 0.8 & 20.3 & 0.99 \\
\hline Note: $D$ is the chord diameter; $\alpha=2 L / D, L$ is the chord \\
length; $\beta=d / D, d$ is the brace diameter; $\gamma=D / 2 T, T$ is \\
the chord thickness; $\tau=t / T, t$ is the brace thickness.
\end{tabular}

glass/vinyl ester, glass/epoxy (Scotch ply 1002), and carbon/epoxy (T300-5208).

\subsection{Modeling of the weld profile}

In order to achieve accurate stresses along the chordbrace intersection, the weld profile should be modeled accurately. AWS [69] presented recommendations for weld profile modeling. In this study, the weld profile along brace-chord intersection satisfies the criteria recommended by AWS [69]. Weld profile was modeled using 20-node solid elements, and the weld properties conform to the chord and brace materials. Besides, some simplifications were made to conceive a smooth and adequate weld profile based on the techniques utilized by Lee [70] and Chiew et al. [71]. Lie et al. [72] well elaborated on the weld profile modeling.

\subsection{FRP Properties}

FRP are composed of two distinguishable parts: fibers and matrices. Applying different fibers and matrixes as the constituents, one could make various compositions. In this study, glass/vinyl ester composite was used as the reference FRP material in the parametric study. Two other FRP materials namely glass/epoxy (Scotch ply 1002) and carbon/epoxy (T300-5208) were used for a parametric study in comparison to glass/vinyl ester. The properties and, also, advantages and disadvantages of carbon and glass fibers and vinyl ester and epoxy matrixes have been previously addressed [73].

GFRPs behave classically with short fatigue lifetimes at high stress amplitudes, and an increasing lifetime as the stress amplitude is lowered, whereas carbon appears unaffected by fatigue until the cycling stress approaches static strength values [74]. Nevertheless, CFRP cyclic behavior depends on the type of CFRP material. Here, this research aimed to show how different types of FRP wrapping materials and their properties could affect the SCF values in a tubular Tjoint. Therefore, due to its novelty, it has been performed with the assumption that the FRP properties remain intact during the loading, and the perfect bond state between FRP and the steel remains valid until the initiation of a fatigue crack on the tube surface. This is the primary research study that investigates the effect of FRP wrapping on SCFs. Further research on the behavior of FRP and its bond to steel needs to be performed numerically and experimentally to reach a firm conclusion about the FRP wrapping effect on SCFs. Thus, it is evident that the application of CFRP to structures, which are susceptible to high-stress amplitude fatigue loading, would be a wiser choice; however, since the fatigue loading is usually of low stress amplitudes in offshore jacket joints, GFRPs can also be a potential alternative. Table 2 demonstrates the properties of the FRPs used in the analyses [75]. In 
Table 2. Fiber Reinforced Polymer (FRP) properties [75].

\begin{tabular}{cccc}
\hline $\begin{array}{c}\text { Engineering } \\
\text { constants }\end{array}$ & $\begin{array}{c}\text { Glass/vinyl } \\
\text { ester }\end{array}$ & $\begin{array}{c}\text { Glass/epoxy } \\
\text { (Scotch ply 1002) }\end{array}$ & $\begin{array}{c}\text { Carbon/epoxy } \\
\text { (T300-5208) }\end{array}$ \\
\hline$E_{1}(\mathrm{MPa})$ & 28000 & 38600 & 132000 \\
$E_{2}(\mathrm{MPa})$ & 7000 & 8270 & 10800 \\
$v_{12}$ & 0.29 & 0.26 & 0.24 \\
$G_{12}(\mathrm{MPa})$ & 4500 & 4140 & 5700 \\
$G_{13}(\mathrm{MPa})$ & 4500 & 4140 & 5700 \\
\hline
\end{tabular}

Note: E: Modulus of elasticity; v: Poisson's ratio; $G$ : Shear modulus.

this table, Subscripts "1" and "2" stand for the fiber longitudinal and transverse directions, respectively.

\subsection{Element type and mesh generation process} In a FE analysis, both shell and 3D brick elements could be used. Depending on the modeled geometry and model outputs, the type of element for the analysis could be chosen. It was important to compromise between model precision and the computational time required to analyze the model [14]. In this study, ABAQUS 3D element type C3D20, which is a 20-node quadratic brick, was used to model the joint geometry and weld profile in order to achieve a more accurate and detailed stress distribution at the joint intersection zone.

FRP material was modeled using shell elements that were defined as a skin layer covering the tube surfaces by sharing interface nodes. Here, a perfect bond state was considered, and no cohesive/adhesive element was modeled at the FRP and the steel substrate interface [65]. ABAQUS element type S4R, which is a 4-node doubly curved thin or thick shell with reduced integration, was used to model the FRP layers. The mesh generation process and mesh dimensions highly depend on the geometrical complexity of the model. Different sub-zone mesh generation methods were used for weld profile, HSS region, FRP wrapping area, and other regions of the joint, which were far away from the weld. In this method, the mesh in the HSS region was much finer than that in the other zones due to the demand for high computational accuracy. FRP wrapping areas had coarser meshes, but were fine enough to sustain accuracy. The highly coarse meshes were attributable to regions far away from the weld in which the mesh quality did not have a remarkable effect on the FE results and, in particular, on the stress distribution along the weld toe. Figure 1 shows the mesh generated for the tubular T-joint.

Prior to the generation of the $58 \mathrm{FE}$ models for analysis, the optimum mesh pattern was obtained by sensitivity analyses with different mesh densities in order to balance the accuracy of the results through the computational effort with emphasis on the accuracy of the predictions. As shown in Figure 1(a), by

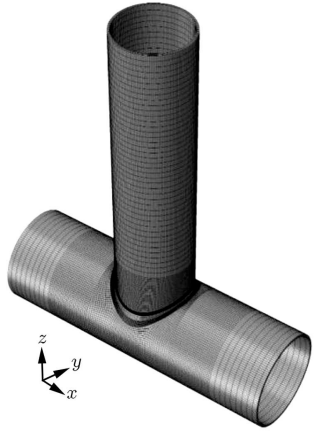

(a) Isometric view

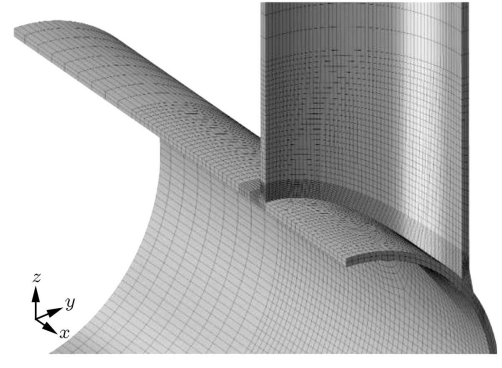

(b) Mesh enlargement
Figure 1. The mesh generated for the T-joint using the sub-zone method.

approaching chord ends from the joint intersection area, in which the stresses must be calculated and read with high delicacy, average element dimensions increased to $30 \mathrm{~mm}$. Average element sizes in the areas in which the FRP was applied to the joint were around $10 \mathrm{~mm}$.

\subsection{Boundary conditions}

As previously mentioned, the tubular T-joint in this study was modeled based on the JISSP project, joint ref. 1-3. Although the joint geometry is symmetric with respect to $\mathrm{x}-\mathrm{z}$ and $\mathrm{y}-\mathrm{z}$ planes, the entire joint was modeled because of the non-symmetric nature of FRP, as well as arbitrary fiber orientations and ply stacking. The chord end fixity of joints in offshore structures ranges from 'almost fixed' to 'almost pinned', which is generally closer to 'almost fixed' [76]. In this research, chord ends are assumed to be fixed in order to represent the actual conditions of the experiments.

\subsection{Analysis and extrapolation method}

In order to determine the SCFs in a tubular joint, linear elastic numerical analysis is required [77]. Here, a load controlled static analysis was conducted such that the maximum strains in the tubular joint stayed in the linear elastic part of the stress-strain relationship. The axial load applied at the top of the brace member varies linearly from zero to the maximum selected load. Young's modulus and Poisson's ratio of steel were taken to be $207 \mathrm{GPa}$ and 0.3 , respectively [11]. In order to 
Table 3. Comparison of Finite Element (FE) results and experimental data and predictions of Lioyd's Register (LR) [11] and API [4] equations.

\begin{tabular}{cccccccc}
\hline Position & Test & LR equation & API equation & FEM $^{\mathrm{a}}$ & $e_{1}(\%)$ & $e_{2}(\%)$ & $e_{3}(\%)$ \\
\hline Crown & 5.4 & 3.94 & 3.85 & 5.3 & 27.0 & 28.7 & 1.9 \\
Saddle & 11.4 & 10.54 & 12.13 & 11.1 & 7.5 & 6.4 & 2.6 \\
\hline
\end{tabular}

${ }^{a}$ FEM: Finite Element Model.

estimate the SCFs, the method introduced by IIW-XV$\mathrm{E}[78]$ was used. In this method, the peak stress at the weld toe was calculated by extrapolating the von Mises stresses linearly at distances of $0.4 T$ and $1.4 T$ from the weld toe, respectively, where $T$ is the thickness of the chord member.

SCFs can also be calculated by normal stresses, i.e., stresses perpendicular to the weld toe. Generally, it is understood that the differences between SCFs calculated from either primary stress or normal stress are negligible such that, for K-joints, they were found to be less than $10 \%$ [16]. Lotfollahi-Yaghin and Ahmadi [26] and Ahmadi et al. [27] used von Mises stresses to calculate the SCFs according to IIW-XVE [78] method, too.

Owing to the complex shape of the spatial curve of the weld toe, it was necessary to mesh the SCF zone (from weld toe to $1.5 \mathrm{~T}$ from weld toe) separately. There were 15 meshed elements perpendicular to the weld toe; therefore, every mesh element had a dimension equal to $0.1 \mathrm{~T}$. Von Mises stresses in the fourth and fourteenth elements corresponding to the above-mentioned distances from the weld toe were extracted, and the stress at the weld toe was extrapolated accordingly. SCF was then reckoned by dividing the calculated stress by the nominal stress at the brace.

\subsection{Un-stiffened model validation}

In order to validate the FE model, Lloyd's Register equations [11], API [4] equations, and test results [11] for JISSP joint ref. 1.3 were compared with the numeri- cal analysis results. Table 3 summarizes the verification results in saddle and crown positions separately. In this table, $e_{1}$ and $e_{2}$ show the percentage of the relative difference of the Lloyd's Register (LR) [11] and API [4] equations prediction from test results, respectively, and $e_{3}$ denotes the percentage of relative difference between the results of the FE model and experimental results.

According to Table 3, the FE model predicts the SCFs at crown and saddle positions with excellent accuracy.

\section{Parametric study of FRP effects on the SCFs}

This section presents the results of the numerical parametric study carried out to investigate the effect of parameters related to the FRP addressed in the above paragraphs. Analyses were carried out in three phases. Firstly, the chord alone was strengthened in order to investigate the effects of strengthening the chord member on SCFs. Secondly, FRP was applied only to the brace to study the same effects on the brace member; finally, in the third phase, chord and brace members were strengthened altogether. Figure 2 presents the FRP wrapping schemes in the numerical models.

Due to the symmetry of stress distributions in a T-joint, results are presented along a $90^{\circ}$ polar angle (a quarter of chord-brace intersection zone), which starts from the crown point and ends at the saddle point. Figure 3 shows this $90^{\circ}$ polar angle.

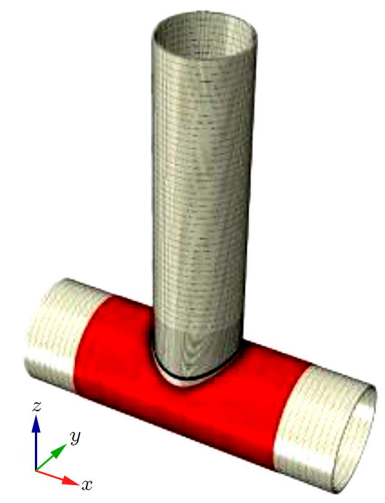

(a) Chord strengthening

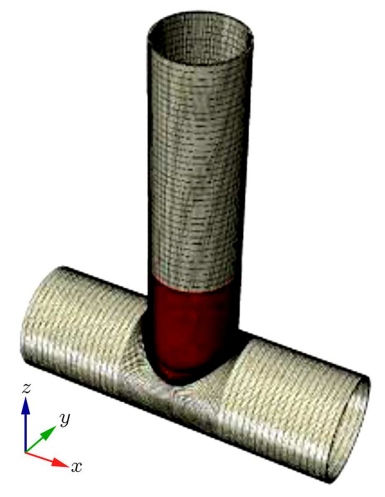

(b) Brace strengthening

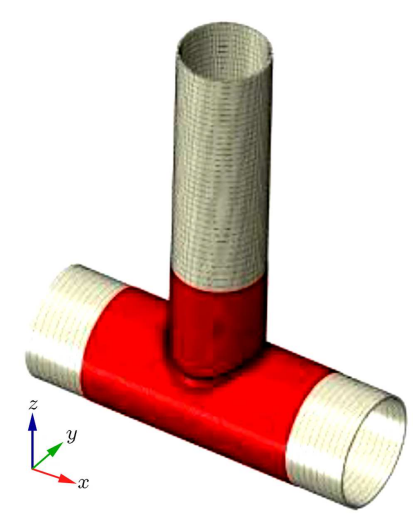

(c) Chord and brace strengthening

Figure 2. A typical Fiber-Reinforced Polymer (FRP) wrapped T-joint. 


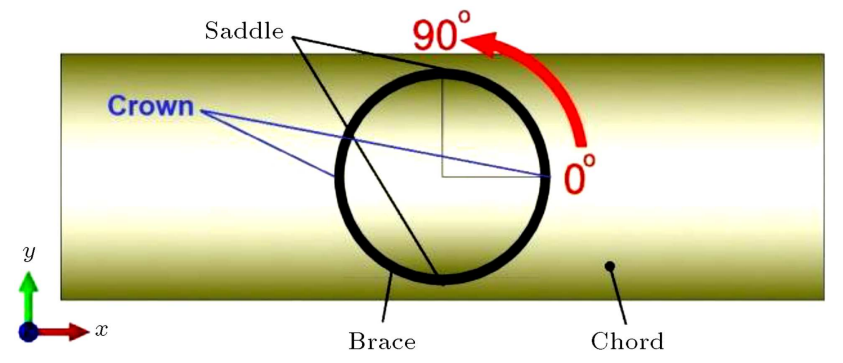

Figure 3. Definition of the $90^{\circ}$ polar angle between the crown and saddle points (plan view of the T-joint).

\subsection{Effect of the fiber orientation}

In an FRP system, fibers are the dominant constituent, and because the load-carrying capacity of a composite system highly depends on its fibers direction, one of the main objectives of FRP strengthening design is to place the fibers in such a way that they are able to contribute efficiently to load-carrying capability [73]. In this section, the effect of fiber orientation $\left(\theta_{f}\right)$ on the SCFs is investigated. Figure 4 shows the applied FRP reinforcement directions. It should be noted that, according to Figure 4 , the $0^{\circ}$ fiber orientation on the brace member was along its longitudinal axis, while this orientation on the chord member was along the transverse (hoop) direction.

Figure 5(a) illustrates the relative values of SCFs (SCF in strengthened joints, $S C F_{s}$, against unstrengthened joints, $S C F_{u}$ ) in phase 1 for various fiber orientations of a $1 \mathrm{~mm}$ thick GFRP (glass/vinyl ester) composite covering the chord member at a length of $1 \mathrm{D}$ (in which, $D$ is the chord diameter) in a quarter portion of the length of the chord-brace intersection curve. According to Figure 5(a), using fibers in $0^{\circ}$ and $90^{\circ}$ orientations had the most decreasing effect near the

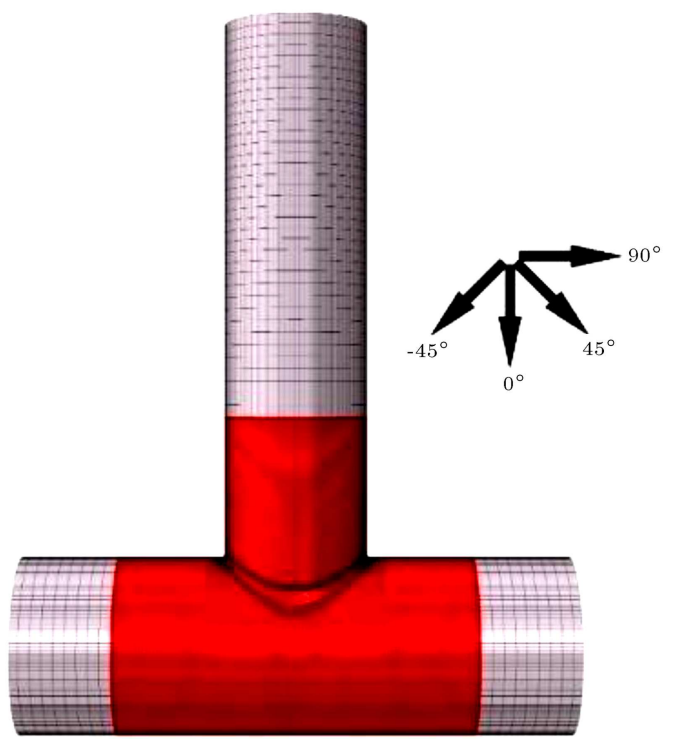

Figure 4. Directions of the Fiber-Reinforced Polymer (FRP) plies $\left(\theta_{f}\right)$.

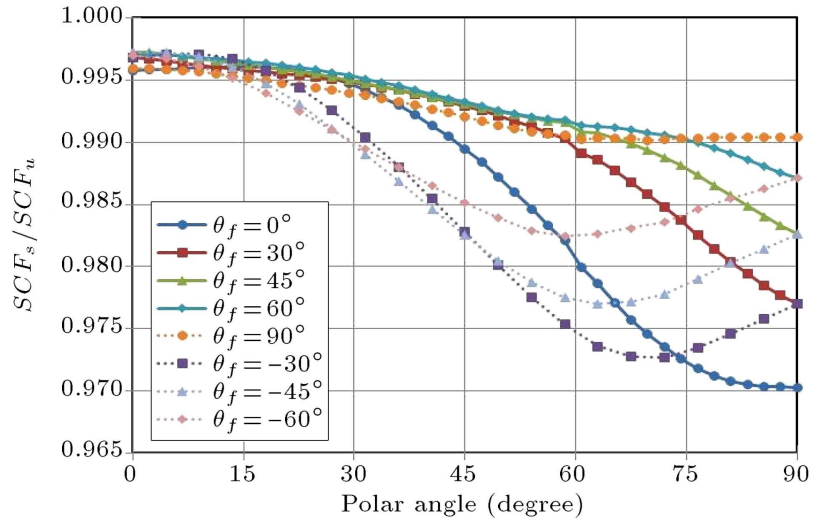

(a) Chord strengthening

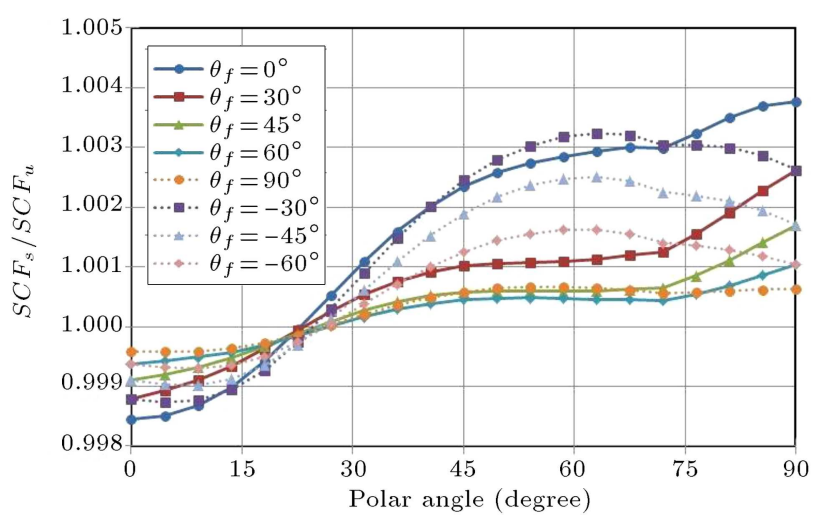

(b) Brace strengthening

Figure 5. Ratio of Stress Concentration Factor (SCF) distributions in the FRP-strengthened tubular T-joint to SCF distribution in un-strengthened joint with different fiber orientations.

crown point (polar angle $=0^{\circ}$ ). Circulating from the crown point, fibers with $-45^{\circ}$ orientation reduced the SCF more effectively than the other orientations. From $45^{\circ}$ to almost $75^{\circ},-30^{\circ}$ orientation had the highest decreasing effect; from $75^{\circ}$ to the saddle point (polar angle $\left.=90^{\circ}\right), 0^{\circ}$ orientation of fibers caused the most significant drop in the SCF. According to Figure 5(a), the maximum decrease of SCF values for a $1 \mathrm{~mm}$ thick FRP ply was observed for $0^{\circ}$ fiber orientation at the saddle position, which was about $3 \%$.

Figure 6(a) presents the effect of fiber orientations on SCF reduction at crown and saddle points of the T-joint. It is evident that $0^{\circ}$ and $90^{\circ}$ orientations had the most decreasing effect and, in turn, fibers with $45^{\circ}$ orientation had the lowest effect on SCF values. According to this figure, similar effects on $\mathrm{SCF}$ at the crown position for both positive and negative orientations were observed. The continuous line in Figure 6(a), which shows the relative SCF values at the saddle point, indicates that, apart from $0^{\circ}$ orientation, FRP effectiveness in decreasing SCF values at the saddle position had a descending manner.

Figure 5(b) represents the second phase of the analysis as how brace reinforcement affects the SCF 


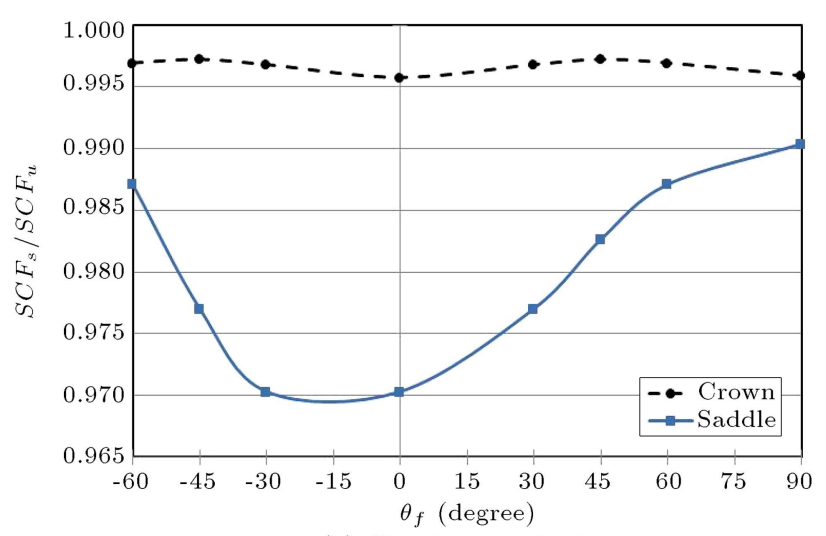

(a) Chord strengthening

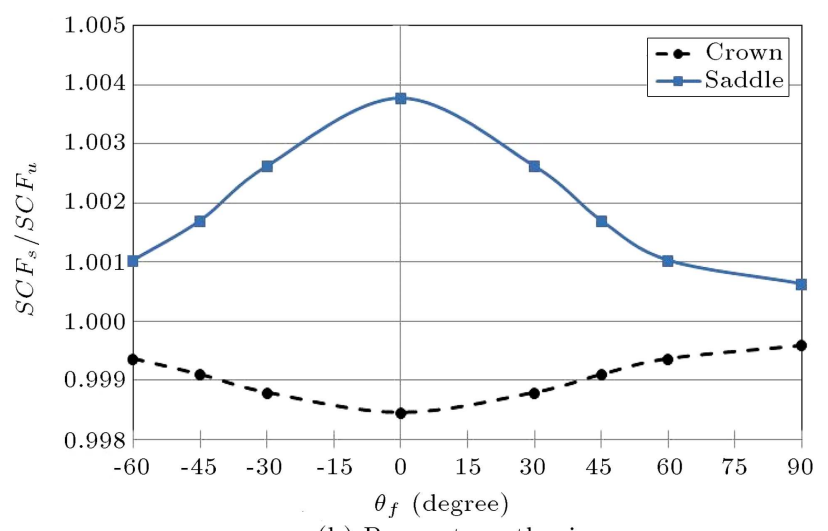

(b) Brace strengthening

Figure 6. Ratio of Stress Concentration Factor (SCF) in the FRP-strengthened tubular T-joint with different fiber orientations to SCF in un-stiffened joint for crown and saddle points.

values along the chord-brace intersection curve (one quarter portion). It is shown that, regardless of the fiber orientation, for polar angles between $0^{\circ}$ (crown point) and $20^{\circ}$, brace wrapping decreased the SCF values very slightly, in which the most effective orientation was $0^{\circ}$. In contrast, for polar angles higher than $20^{\circ}$ up to $90^{\circ}$, brace reinforcement had a slight increasing effect on SCF values. As Figure 5(b) shows, the least decreasing effect of brace strengthening on SCF values was observed at the saddle point, where FRP layers with $0^{\circ}$ fibers were used. This amount was around $0.35 \%$, which is negligible.

Figure 6(b) illustrates the change in relative SCFs at crown and saddle positions for different fiber orientations. For the crown point, it is indicated that increasing the orientation angle from $0^{\circ}$ to $90^{\circ}$ scales down the decreasing effect of FRP reinforcement on the SCF values. This effect was similar for negative values of fiber orientation angle. The relative SCF values at the saddle position for different fiber orientations are presented with a continuous line in Figure 6(b). Accordingly, changing the fiber orientation from $0^{\circ}$ decreased the effectiveness of the FRP wrapping in reducing the $\mathrm{SCF}$ values at the saddle point.

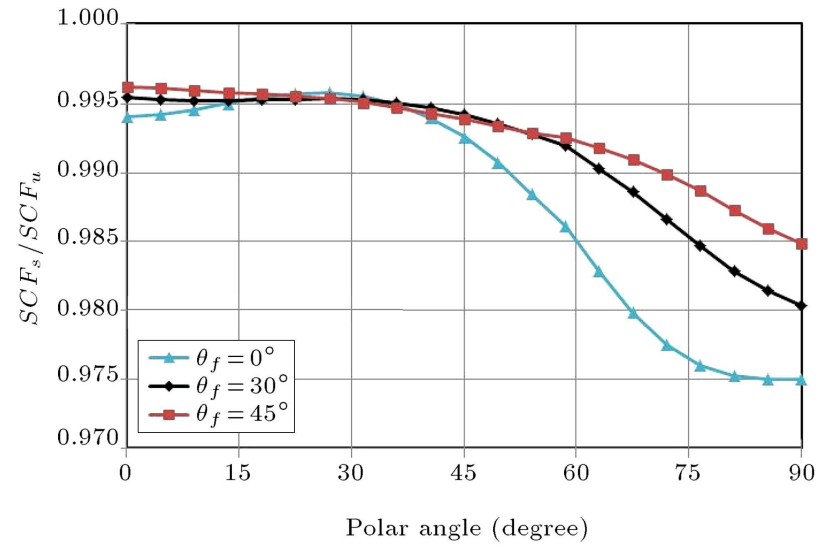

Figure 7. Ratio of Stress Concentration Factor (SCF) distributions in the FRP-strengthened tubular T-joint with different fiber orientations to SCF distribution in un-strengthened joint.

In order to examine the effect of fiber orientation on an FRP-wrapped joint (chord and brace simultaneously), three different FRP layups with $0^{\circ}, 30^{\circ}$, and $45^{\circ}$ fiber orientations were applied to the T-joint, and the pertinent results are shown in Figure 7.

According to this figure, $0^{\circ}$ orientation had the highest decreasing effect on the SCF values. Of note, due to the adverse effect of brace wrapping on SCF reduction, the relative values of SCFs in a joint in which both chord and brace members were strengthened were higher than those of a joint with only a strengthened chord. In this case, the decreasing effect of the reinforcement was $2.5 \%$.

\subsection{Effect of the FRP thickness}

This section presents the effect of FRP ply thickness on the values of SCFs. Although it is already known that, owing to the improvement of mechanical properties, increasing the FRP layup thickness up to a certain level decreases the level of stresses and, hence, reduces the values of SCFs. The numerical investigations performed in this section evaluate the performance and effectiveness of the FRP reinforcement. These analyses were performed for six different FRP thicknesses (i.e., $1,2,4,6,8$, and $10 \mathrm{~mm})$. The relative thicknesses (the thickness of FRP layer divided by the member thickness) were used to illustrate the effect of FRP thickness on SCF values in Figure 8(a).

Figure 8(a) presents the results of numerical analysis on FRP-strengthened chord of a T-joint with different layup thicknesses along the chord-brace intersection. According to this figure, increasing the FRP thickness on the chord member reduced the SCF values and, subsequently, enhanced the fatigue life of the joint. As evident from this figure, the decreasing effect of wrapping the chord member on the SCFs increased by moving from $0^{\circ}$ (crown) to $90^{\circ}$ (saddle), which reached up to $27 \%$. It must be noted that all FRPs had a fiber 


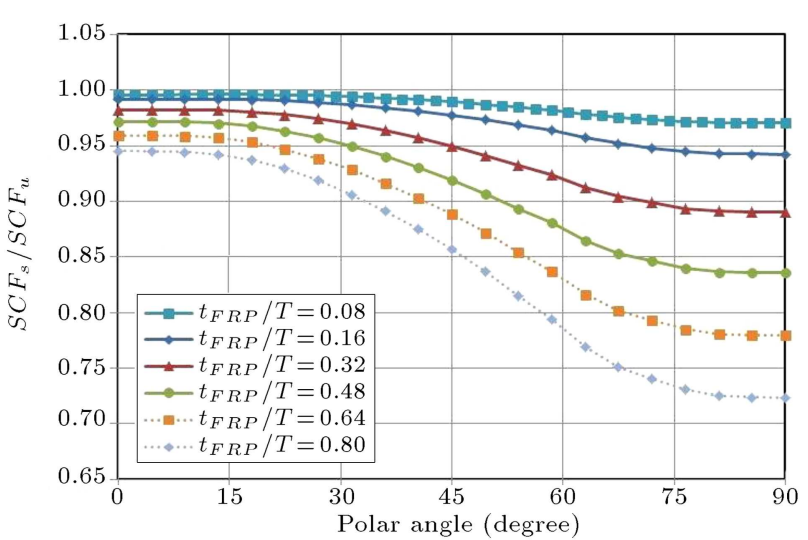

(a) Chord strengthening

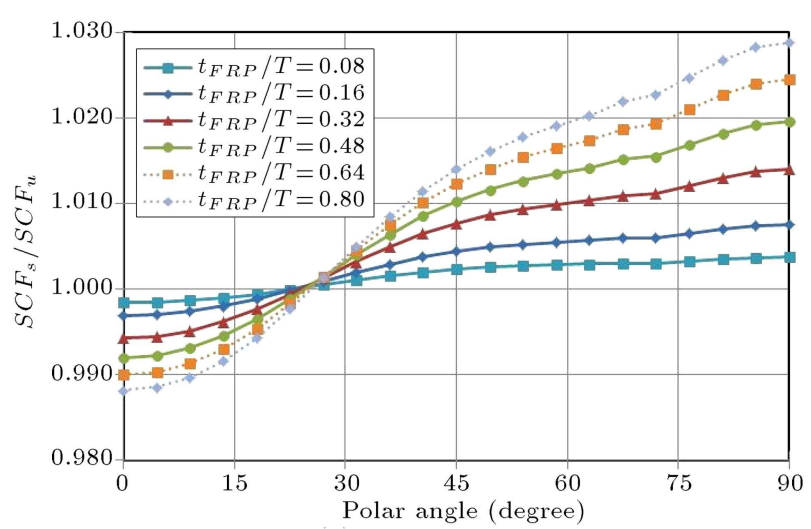

(b) Brace strengthening

Figure 8. Ratio of Stress Concentration Factor (SCF) distributions in the FRP-strengthened tubular T-joint with different FRP thicknesses to SCF distribution in un-strengthened joint.

orientation of $0^{\circ}$ and were made of glass/vinyl ester composite.

FPR strengthening of the chord member of a Tjoint at crown and saddle positions is illustrated in Figure 9(a) with dashed and continuous lines, respectively. This figure shows the effectiveness of FRP in decreasing the SCFs with a linear trend for different FRP thicknesses (i.e., higher FRP thickness leads to lower SCFs at crown and saddle positions). It is worth noting that, for parametric study purposes, FRP thicknesses of $1 \mathrm{~mm}$ up to $10 \mathrm{~mm}$ were utilized theoretically. In practical applications, FRP wrapping thicknesses should be selected with care, since a different behavior is exhibited when a thick layer of composite is applied, making it not cost effective at all.

Figure $8(\mathrm{~b})$ shows how the FRP relative thickness on the brace member could affect the SCF values at the chord-brace intersection.

As demonstrated in this figure, by circulating from the crown point $\left(0^{\circ}\right)$ to almost $25^{\circ}$ at the polar angle along the intersection curve, the decreasing effect of FRP thickness was scaled down, and by moving from $20^{\circ}$ to $90^{\circ}$ (saddle point), the reverse effect was observed. The reverse effect of brace strengthening on

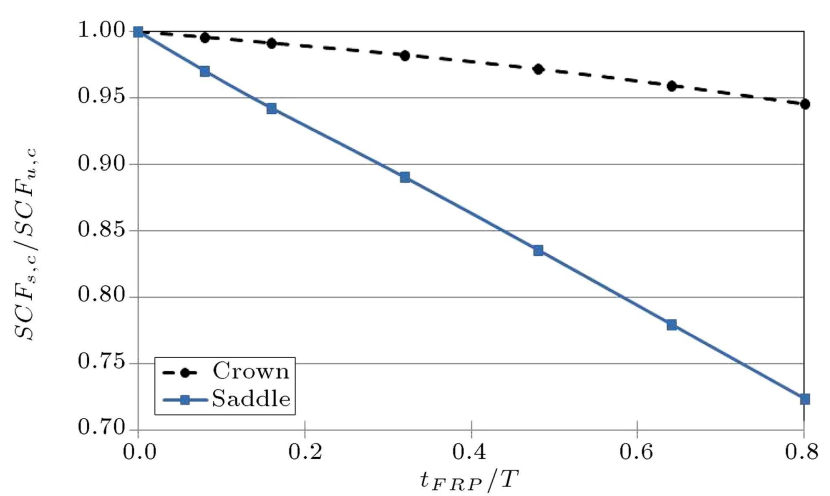

(a) Chord strengthening

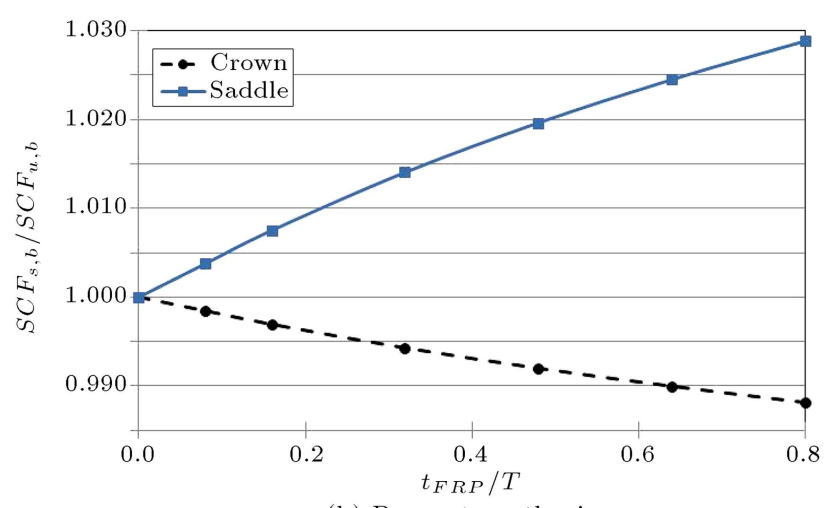

(b) Brace strengthening

Figure 9. Ratio of Stress Concentration Factor (SCF) in the FRP-strengthened tubular T-joint with different FRP thicknesses to SCF in un-strengthened joint for crown and saddle points.

SCFs could be seen at the saddle point (polar angle: $90^{\circ}$ ) for the maximum relative thickness, which was about $2.8 \%$. Strengthening the brace member only decreased the SCF values at the crown position, while it had an increasing effect on SCFs at the saddle point (Figure 9(b)).

According to this figure, the effect of brace FRP thickness had an almost linear, yet adverse, trend in the case of crown and saddle positions.

Figure 10 presents the relative SCF values for three different relative FRP thicknesses in one quarter of the chord-brace intersection, respectively. The effectiveness of FRP thickness increment was scaled up by moving from the crown position (2.5\% decrease) to the saddle point ( $9 \%$ decrease).

\subsection{Length of FRP wrapping}

According to Lesani et al. [66], the prime function of FRP wrapping length, especially on the chord member, was to cover the entire the chord surface area influenced by the brace loading to balance the state of stresses and deformations. The effect of this parameter is investigated in this section. Figure 11 shows the relative wrapping lengths $\left(L_{s}\right)$ for chord and brace schematically. The first analysis was carried out for a relative length of 0.5 times the member diameter. The 


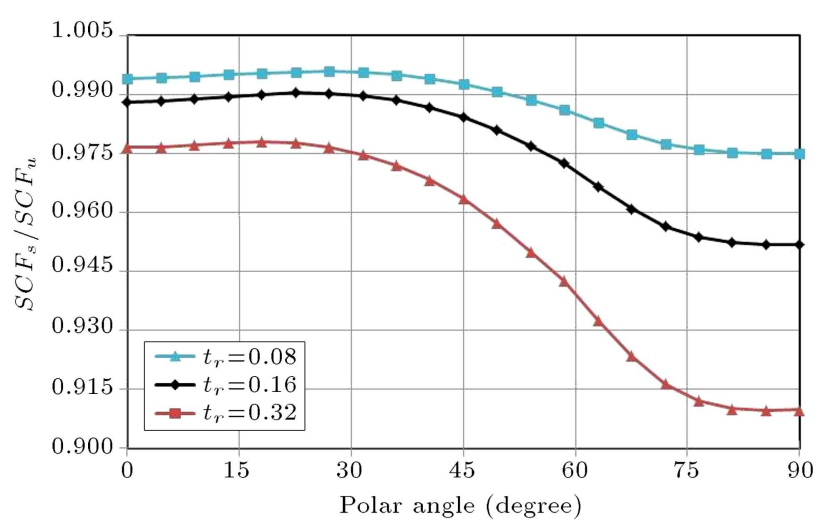

Figure 10. Ratio of Stress Concentration Factor (SCF) distributions in the FRP-strengthened tubular T-joint with different FRP thicknesses to Stress Concentration Factor(SCF) distribution in un-strengthened joint $\left(t_{r}\right.$ : $t_{F R P}$ divided by chord and brace thickness).

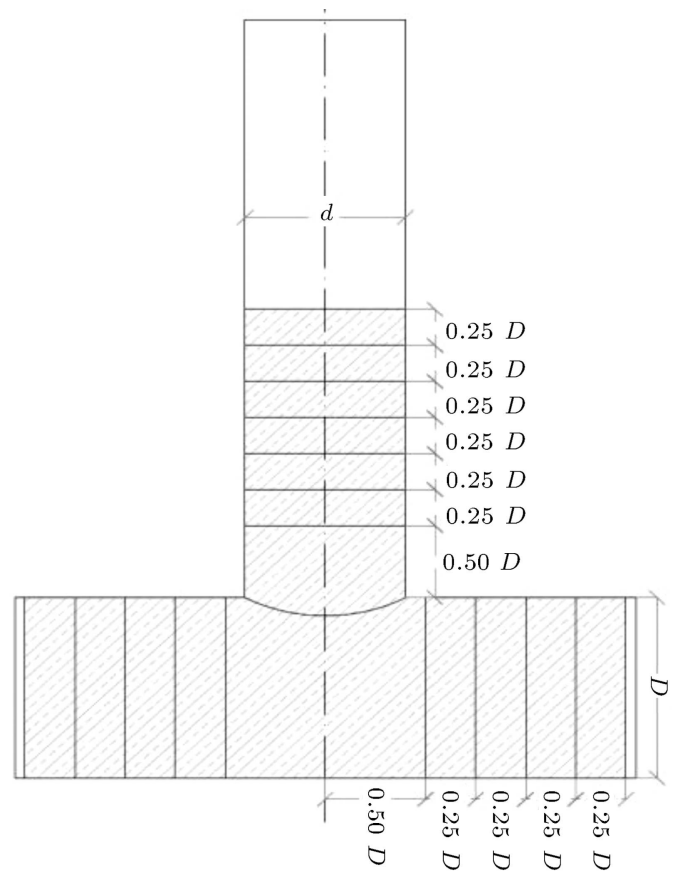

Figure 11. Schematic of strengthening length $\left(L_{s}\right)$ for chord and brace members.

rest of the analyses were performed by increasing the wrapping length by 0.25 times the member diameter.

Relative SCF values for five different relative lengths (length of FRP wrapping to chord diameter) used for strengthening the chord member are presented in Figure 12(a). All FRPs had a fiber orientation of $0^{\circ}$ and were made of glass/vinyl ester composite. Focusing on this figure reveals that increasing the FRP wrapping length led to a very slight decrease in the SCF values.

According to Figure 13(a), at the crown position of a wrapped chord member, a change in FRP wrapping length had almost no effect on the SCFs. Chord member wrapping length had a slight effect on the

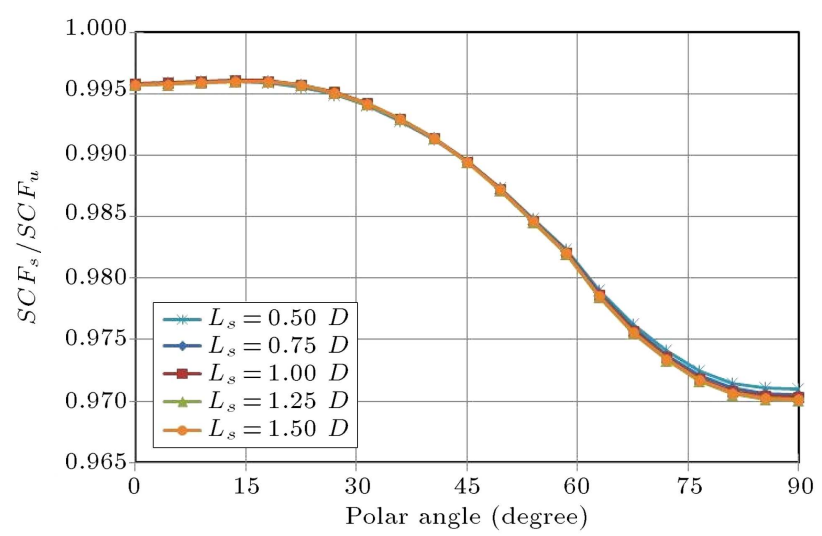

(a) Chord strengthening

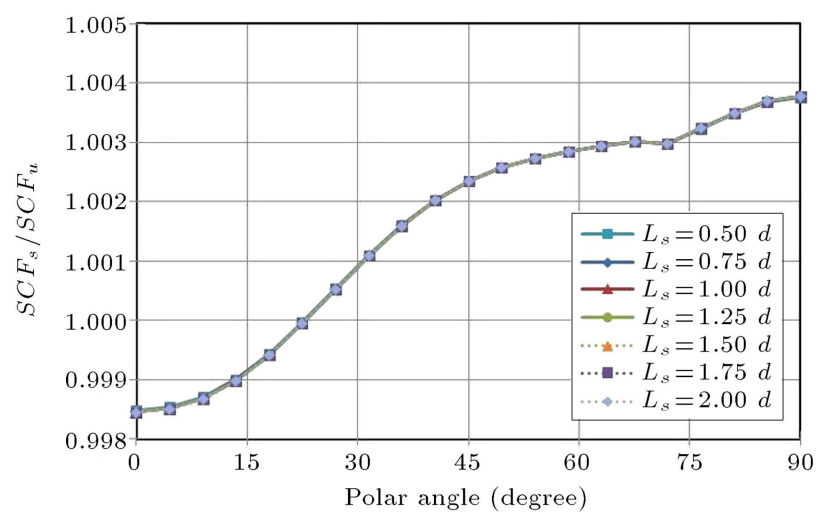

(b) Brace strengthening

Figure 12. Ratio of Stress Concentration Factor (SCF) distribution in the FRP-strengthened tubular T-joint with different FRP wrapping lengths $\left(L_{s}\right.$ : FRP length on Chord, $l_{s}$ : FRP length on brace) to SCF distribution in un-strengthened joint $(D$ : chord diameter, $d$ : brace diameter).

saddle position with a linear trend. According to this figure, regardless of the FRP wrapping length, if the hot spot stress area was covered by a $1 \mathrm{~mm}$ thick glass/vinyl ester FRP composite, the SCF values dropped by 0.5 and $3 \%$ at the crown and saddle positions, respectively.

The effect of FRP wrapping length on the brace member only was also investigated, and the relevant results are presented in Figure 12 (b) at a $90^{\circ}$ polar angle along the chord-brace intersection. It is clearly seen from this figure that brace strengthening had almost no effect on the SCF values.

Figure 13(b) shows the effectiveness of FRP wrapping of brace member in the SCFs at the crown and saddle positions.

It could be envisaged from the values in the figure that the wrapping length had almost no effect on the SCFs.

Figure 14(a) demonstrates the effect of change in FRP wrapping length of the chord member when both chord and brace members were strengthened. In this figure, the length of FRP wrapping at brace was equal 


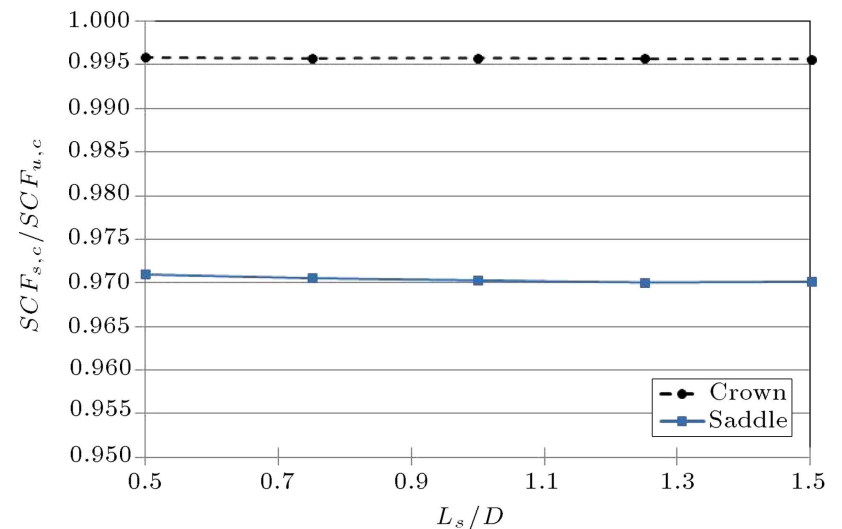

(a) Chord strengthening

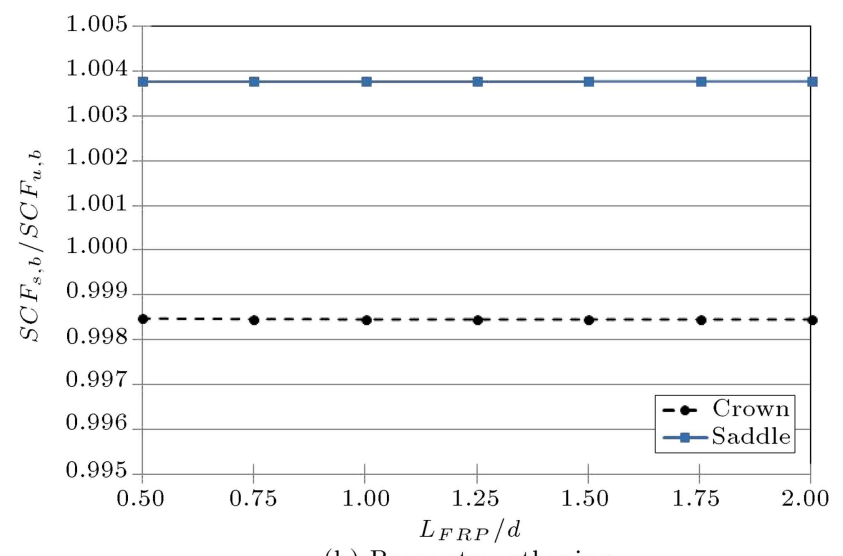

(b) Brace strengthening

Figure 13. Ratio of Stress Concentration Factor (SCF) in the FRP-strengthened tubular T-joint with different FRP wrapping lengths to SCF in un-strengthened joint for crown and saddle points.

to $1 d$ ( $d$ is the brace member diameter) and remained constant for the brace member.

Figure 14(b) presents the effect of changing brace wrapping length when chord member wrapping length remained constant at $1 D$ ( $D$ is the chord member diameter) for the similar case. According to this figure, the increase of FRP wrapping length of the chord member had a slight decreasing effect on the SCFs, while almost no effect on SCF values was recorded for the brace member.

\subsection{Effect of the FRP material}

Change in fiber and/or matrix material properties corresponds to a change in FRP mechanical properties. This strongly affects the joint stress distributions and, subsequently, the SCF values. As mentioned earlier, in this study, two kinds of fibers (glass and carbon) with two different matrices (epoxy and vinyl ester) were used as the strengthening materials, and their effects on SCF distribution along the chord-brace intersection were investigated. Three kinds of FRP materials, namely glass-vinyl ester, glass-epoxy, and carbon-epoxy, were used as the strengthening materials

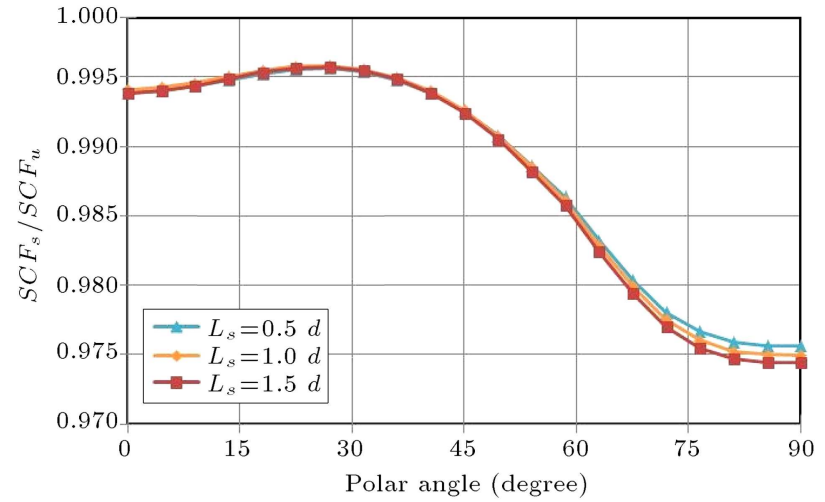

(a) Chord strengthening

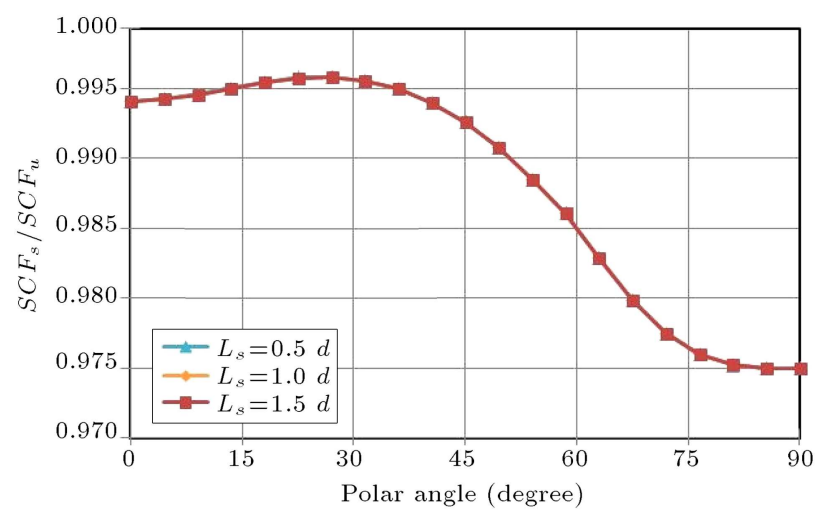

(b) Brace strengthening

Figure 14. Ratio of Stress Concentration Factor (SCF) distribution in the FRP-strengthened tubular T-joint with different FRP wrapping lengths to SCF distribution in un-strengthened joint.

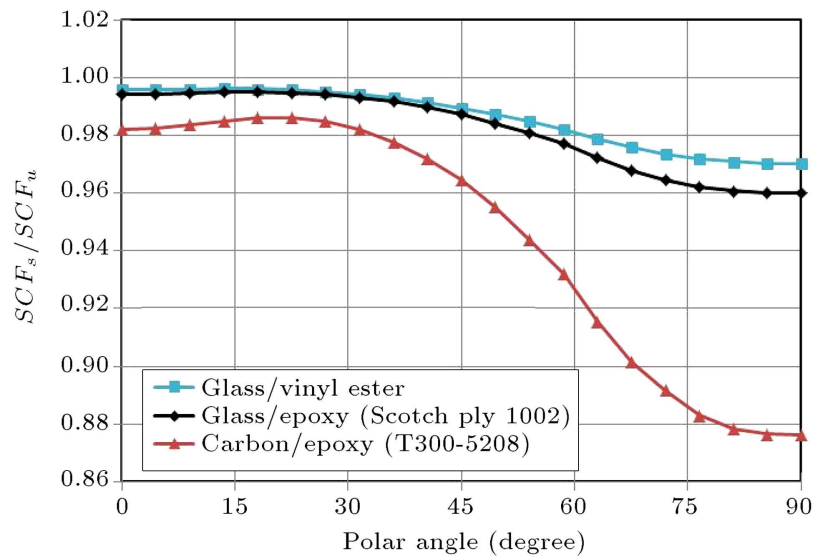

Figure 15. Ratio of Stress Concentration Factor (SCF) distribution in the FRP-strengthened tubular T-joint chord with different FRP materials to Stress Concentration Factor (SCF) distribution in un-strengthened joint.

with $0^{\circ}$ orientation fibers having a thickness of $1 \mathrm{~mm}$ and a wrapping length equal to one times the diameter of the relative strengthened member. The effects of changing FRP material when only the chord member was strengthened are presented in Figure 15. 


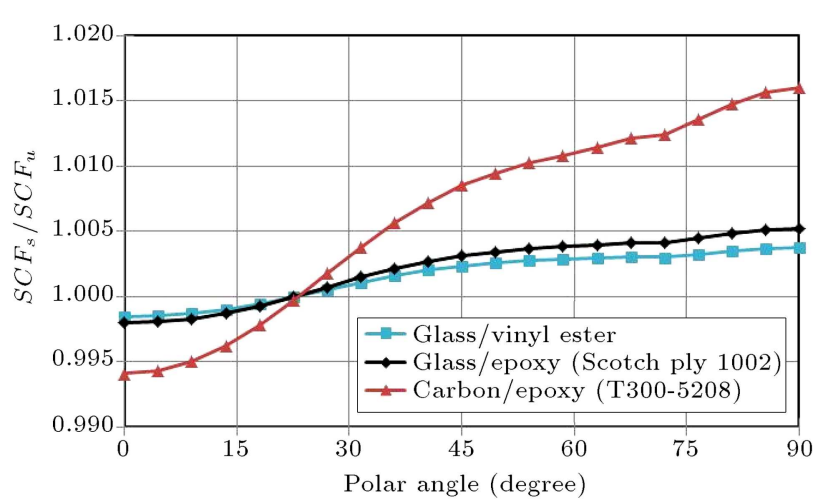

Figure 16. Ratio of Stress Concentration Factor (SCF) distribution in the FRP-strengthened tubular T-joint brace with different FRP materials to SCF distribution in un-strengthened joint.

Stiffer FRP material (higher mechanical properties) showed greater effectiveness in decreasing the SCF values. As clearly envisaged from this figure, the application of carbon-epoxy material had the effectiveness degree of about three times the GFRP material in SCF reduction, which was about $12 \%$ at the saddle point. As previously stated, strengthening the brace member had an increasing effect on SCFs for polar angles between $20^{\circ}$ and $90^{\circ}$ (saddle point) and an adverse effect for $0^{\circ}$ (crown point) to $20^{\circ}$. These effects were amplified by increasing the mechanical properties of the FRP materials (Figure 16).

The adverse effect of using higher modulus materials on brace member only was about maximum $1.6 \%$ at the saddle point. Figure 17 presents the effect of different FRP material on SCF values when the chord and brace were both strengthened in a T-joint.

Based on this figure, adverse effects from chord and brace strengthening compromise each other at various polar angles. Thus, the maximum effectiveness of the $1 \mathrm{~mm}$ thick FRP with carbon-epoxy material and a $0^{\circ}$ fiber orientation was about $10 \%$ at the saddle point.

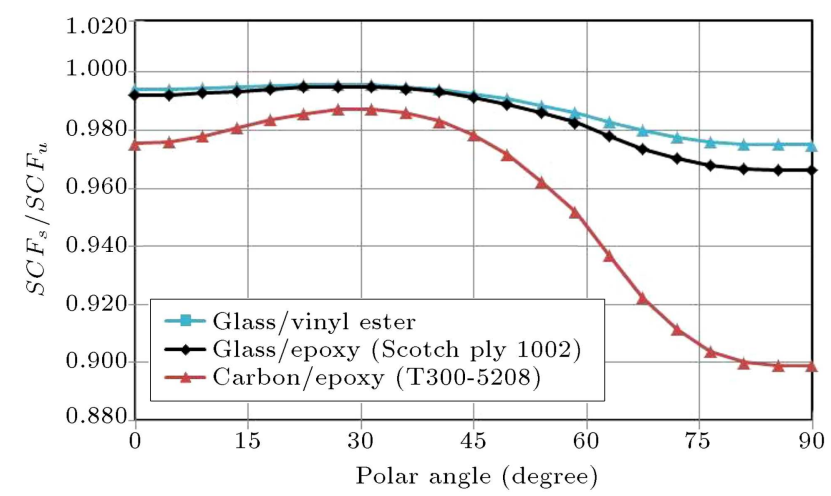

Figure 17. Ratio of Stress Concentration Factor (SCF) distribution in the FRP-strengthened tubular T-joint with different FRP materials to SCF distribution in un-strengthened joint.

\section{Conclusion}

In this research, Stress Concentration Factor (SCF) values at a $90^{\circ}$ polar angle in one quarter of the chordbrace intersection area in an axially loaded tubular $\mathrm{T}$ joint strengthened by Fiber-Reinforced Polymer (FRP) wrapping were investigated. The effect of various FRP parameters such as fiber orientation, wrapping thickness, length of wrapping, and different FRP materials was studied. In this way, SCF estimations for the fatigue design of FRP-strengthened three-planar T-joints under brace axial loading could be justifiable. Analyses were carried out in three phases: the chord alone was strengthened; FRP was applied only to the brace; both chord and brace members were strengthened.

As a general rule, the FRP wrapping technique decreased the SCF values in a tubular T-joint. However, each FRP-related parameter had its particular effect on the SCFs.

From the analyses performed, the following important conclusions can be drawn:

- The effect of fiber orientations using fibers at $0^{\circ}$ and $90^{\circ}$ orientations on the chord member had the most decreasing effect near the crown point (polar angle $=0)$. For both of the positive and negative fiber orientations, moving towards the saddle point from the $0^{\circ}$ orientation scaled down the FRP effectiveness in decreasing SCF values at the saddle position. Fiber orientation in FRP, which was used for brace strengthening, regardless of the utilized fiber orientation, had a slightly increasing effect on SCF values;

- Increasing the FRP thickness on the chord member reduced the SCF values. The effectiveness of FRP wrapping of the chord member in decreasing the SCFs was increased by moving from $0^{\circ}$ (crown) towards $90^{\circ}$ (saddle). Increasing the thickness of FRP wrapping used for strengthening the chord member of a $\mathrm{T}$-joint at the crown and saddle positions decreased the SCFs with a linear trend. Strengthening the brace member only decreased the SCF values at the crown position, while it had an increasing effect on SCFs at the saddle point;

- Change in FRP wrapping length for a chord or brace strengthened T-joint had almost no effect on SCFs. Chord member wrapping length is much more effective in the saddle position, which had almost a linear trend;

- Change of fiber and/or matrix material properties corresponds to that in FRP mechanical properties. The application of FRP material with higher values of mechanical properties showed more effectiveness in decreasing the SCF values. Among the common composite material, carbon-epoxy had the effectiveness of about three times GFRP in SCF reduction; 
- Due to the better fatigue performance of CFRP materials in comparison to other composite materials such as GFRP and based on the findings of this study, it is highly recommended to use CFRP composites as wrapping and strengthening material for fatigue life extension of tubular joints.

\section{References}

1. Jia, J. "An efficient nonlinear dynamic approach for calculating wave induced fatigue damage of offshore structures and its industrial applications for lifetime extension", Appl. Ocean Res., 30, pp. 189-198 (2008).

2. Lee, M.M.K. "Estimation of stress concentrations in single-sided welds in offshore tubular joints", Int. J. Fatigue, 21, pp. 895-908 (1999).

3. Liu, G., Zhao, X., and Huang, Y. "Prediction of stress distribution along the intersection of tubular T-joints by a novel structural stress approach", Int. J. Fatigue, 80, pp. 216-230 (2015).

4. API RP 2A WSD (22nd Edition), Recommended Practice for Planning, Designing and Constructing Fixed Offshore Platforms-working Stress Design, American Petroleum Institute, USA (2014).

5. Kuang, J.G., Potvin, A.B., and Leick, R.D. "Stress concentration in tubular joints", Proceedings of the Offshore Technology Conference (OTC 2205), Houston, Texas, US (1975).

6. Wordsworth, A.C. and Smedley, G.P. "Stress concentrations at unstiffened tubular joints", Proceedings of the European Offshore Steels Research Seminar, Paper 31, Cambridge, UK (1978).

7. Efthymiou, M. and Durkin, S. "Stress concentrations in T/Y and gap/overlap K-joints", Proceedings of the Conference on Behavior of Offshore Structures, Delft, Netherlands (1985).

8. Hellier, A.K., Connolly, M., and Dover, W.D. "Stress concentration factors for tubular Y and T-joints", Int. J. Fatigue, 12, pp. 13-23 (1990).

9. Ramachandra Murthy, D.S., MadhavaRao, A.G., Ghandi, P., and Pant, P.K. "Structural efficiency of internally ring stiffened steel tubular joints", J. Struct. Eng., 118, pp. 3016-3035 (1992).

10. Nwosu, D.I., Swamidas, A.S.J., and Munaswamy, K. "Numerical stress analysis of internal ring-stiffened tubular T-joints", J. Offshore Mec. Arc. Eng., 117, pp. 113-125 (1995).

11. Health and Safety Executive, OTH 354, Stress Concentration Factors for Simple Tubular Joints-Assessment of Existing and Development of New Parametric Formulae, Prepared by Lloyd's Register of Shipping, UK (1997).

12. Morgan, M.R. and Lee, M.M.K. "Parametric equations for distributions of stress concentration factors in tubular K-joints under out-of-plane moment loading", Int. J. Fatigue, 20, pp. 449-461 (1998).
13. Chang, E. and Dover, W.D. "Parametric equations to predict stress distributions along the intersection of tubular X and DT-joints", Int. J. Fatigue, 21, pp. 619-635 (1999).

14. Chang, E. and Dover, W.D. "Prediction of stress distributions along the intersection of tubular $\mathrm{Y}$ and T-joints", Int. J. Fatigue, 21, pp. 361-381 (1999).

15. Karamanos, S.A., Romeijn, A., and Wardenier, J. "Stress concentrations in multi-planar welded CHS XX-connections", J. Constr. Steel Res., 50, pp. 259282 (1999).

16. Karamanos, S.A., Romeijn, A., and Wardenier, J. "Stress concentrations in tubular gap K-joints: mechanics and fatigue design", Eng. Struct., 22, pp. 4-14 (2000).

17. Wingerde, A.M., Packer, J.A., and Wardenier, J. "Simplified SCF formulae and graphs for CHS and RHSK-and KK-connections", J. Constr. Steel Res., 57, pp. 221-252 (2001).

18. Hoon, K.H., Wong, L.K., and Soh, A.K. "Experimental investigation of a doubler-plate reinforced tubular T-joint subjected to combined loadings", J. Constr. Steel Res., 57(9), pp. 1015-1039 (2001).

19. Myers, P.T., Brennan, F.P., and Dover, W.D. "The effect of rack/rib plate on the stress concentration factors in jack-up chords", Marine Struct., 14, pp. 485-505 (2001).

20. Karamanos, S.A., Romeijn, A., and Wardenier, J. "SCF equations in multi-planar welded tubular DTjoints including bending effects", Marine Struct., 15, pp. 157-173 (2002).

21. Gho, W.M. and Gao, F. "Parametric equations for stress concentration factors in completely overlapped tubular K(N)-joints", J. Constr. Steel Res., 60, pp. 1761-1782 (2004).

22. Gao, F. "Stress and strain concentrations of completely overlapped tubular joints under lap brace OPB load", Thin-Walled Struct., 44, pp. 861-871 (2006).

23. Gao, F., Shao, Y.B., and Gho, W.M. "Stress and strain concentration factors of completely overlapped tubular joints under lap brace IPB load", J. Constr. Steel Res., 63, pp. 305-316 (2007).

24. Shao, Y.B. "Proposed equations of stress concentration factor (SCF) for gap tubular K-joints subjected to bending load", Int. J. Space Struct., 19, pp. 137-147 (2004).

25. Woghiren, C.O. and Brennan, F.P. "Weld toe stress concentrations in multiplanar stiffened tubular KK Joints", Int. J. Fatigue, 31, pp. 164-172 (2009).

26. Lotfollahi-Yaghin, M.A. and Ahmadi, H. "Effect of geometrical parameters on SCF distribution along the weld toe of tubular KT-joints under balanced axial loads", Int. J. Fatigue, 32, pp. 703-719 (2010).

27. Ahmadi, H., Lotfollahi-Yaghin, M.A., and Aminfar, M.H. "Geometrical effect on SCF distribution in uniplanar tubular DKT-joints under axial loads", $J$. Constr. Steel Res., 67, pp. 1282-1291 (2011). 
28. Ahmadi, H., Lotfollahi-Yaghin, M.A., and Aminfar, M.H. "Effect of stress concentration factors on the structural integrity assessment of multi-planar offshore tubular DKT-joints based on the fracture mechanics fatigue reliability approach", Ocean Eng., 38, pp. 1883-1893 (2011).

29. Lotfollahi-Yaghin, M.A. and Ahmadi, H. "Geometric stress distribution along the weld toe of the outer brace in two-planar tubular DKT- joints: parametric study and deriving the SCF design equations", Marine Struct., 24, pp. 239-260 (2011).

30. Ahmadi, H., Lotfollahi-Yaghin, M.A., and Aminfar, M.H. "Distribution of weld toe stress concentration factors on the central brace in two-planar CHS DKTconnections of steel offshore structures", Thin-Walled Struct., 49, pp. 1225-1236 (2011).

31. Ahmadi, H., Lotfollahi-Yaghin, M.A., Shao, Y.B., and Aminfar, M.H. "Parametric study and formulation of outer-brace geometric stress concentration factors in internally ring-stiffened tubular KT-joints of offshore structures", Applied Ocean Res., 38, pp. 74-91 (2012).

32. Ahmadi, H., Lotfollahi-Yaghin, M.A., and Shao, Y.B. "Chord-side SCF Distribution of central brace in internally ring-stiffened tubular KT-joints: A geometrically parametric study", Thin-Walled Struct., 70, pp. 93105 (2013).

33. Ahmadi, H. and Lotfollahi-Yaghin, M.A. "Geometrically parametric study of central brace SCFs in offshore three-planar tubular KT-joints", J. of Construct. Steel Res., 71, pp. 149-161 (2012).

34. Ahmadi, H., Lotfollahi-Yaghin, M.A., and Aminfar, M.H. "The development of fatigue design formulas for the outer brace SCFs in offshore three-planar tubular KT-joints", Thin-Walled Struct., 58, pp. 67-78 (2012).

35. Ahmadi, H. and Lotfollahi-Yaghin, M.A. "A robability distribution model for stress concentration factors in multi-planar tubular DKT-joints of steel offshore structures", Appl. Ocean Res., 34, pp. 21-32 (2012).

36. Ahmadi, H. and Lotfollahi-Yaghin, M.A. "Effect of SCFs on $S$-N based fatigue reliability of multi-planar tubular DKT-joints of offshore jacket-type structures", Ships Offshore Struct., 8, pp. 55-72 (2013).

37. Yang, J., Chen, Y., and Hu, K. "Stress concentration factors of negative large eccentricity tubular N-joints under axial compressive loading in vertical brace", Thin-Walled Struct., 96, pp. 359-371 (2015).

38. Ahmadi, H. and Zavvar, E. "The effect of multiplanarity on the SCFs in offshore tubular KT-joints subjected to in-plane and out-of-plane bending loads", Thin-Walled Struct., 106, pp. 148-165 (2016).

39. Nassiraei, H., Lotfollahi-Yaghin, M.A., and Ahmadi, H. "Static strength of collar plate reinforced tubular T/Y-joints under brace compressive loading", J. Constr. Steel Res., 119, pp. 39-49 (2016).
40. Nassiraei, H., Lotfollahi-Yaghin, M.A., and Ahmadi, H. "Static strength of offshore tubular $T / Y$-joints reinforced with collar plate subjected to tensile brace loading", Thin-Walled Struct., 103, pp. 141-156 (2016).

41. Nassiraei, H., Lotfollahi-Yaghin, M.A., and Ahmadi, H. "Structural behavior of tubular $\mathrm{T} / \mathrm{Y}$-joints with collar plate under static in-plane bending", J. Constr. Steel Res., 123, pp. 121-134 (2016).

42. Nassiraei, H., Lotfollahi-Yaghin, M.A., and Ahmadi, H. "Static strength of doubler plate reinforced tubular $\mathrm{T} / \mathrm{Y}$-joints subjected to brace compressive loading: Study of geometrical effects and parametric formulation", Thin-Walled Struct., 107, pp. 231-247 (2016).

43. Nassiraei, H., Lotfollahi-Yaghin, M.A., and Ahmadi, H. "Static performance of doubler plate reinforced tubular T/Y-joints subjected to brace tension", ThinWalled Struct., 108, pp. 138-152 (2016).

44. Nassiraei, H., Lotfollahi-Yaghin, M.A., Ahmadi, H., and Zhu, L. "Static strength of doubler plate reinforced tubular T/Y-joints under in-plane bending load", $J$. Constr. Steel Res., 136, pp. 49-64 (2017).

45. Nassiraei, H., Zhu, L., Lotfollahi-Yaghin, M.A., and Ahmadi, H. "Static capacity of tubular X-joints reinforced with collar plate subjected to brace compression", Thin-Walled Struct., 119, pp. 256-265 (2017).

46. Shao, Y. "Static strength of collar-plate reinforced tubular T-joints under axial loading", Steel Comp. Struct., An Int. J., 21(2), pp. 323-342 (2016).

47. Ahmadi, H., Mohammadi, A.H., and Yeganeh, A. "Probability density functions of SCFs in internally ring-stiffened tubular KT-joints of offshore structures subjected to axial loading", Thin-Walled Struct., 94, pp. 485-499 (2015).

48. Ahmadi, H., Yeganeh, A., Mohammadi, A.H., and Zavvar, E. "Probabilistic analysis of stress concentration factors in tubular KT-joints reinforced with internal ring stiffeners under in-plane bending loads", Thin-Walled Struct., 99, pp. 58-75 (2016).

49. Ahmadi, H. "A probability distribution model for SCFs in internally ring-stiffened tubular KT-joints of offshore structures subjected to out-of-plane bending loads", Ocean Eng., 116, pp. 184-199 (2016).

50. Xu, F., Chen, J., and Jin, W.L. "Experimental investigation of SCF distribution for thin-walled concretefilled CHS joints under axial tension loading", ThinWalled Struct., 93, pp. 149-157 (2015).

51. Chen, Y., Hu, K., and Yang, J. "Investigation on SCFs of concrete-filled circular chord and square braces K-joints under balanced axial loading", Steel Comp. Struct., An Int. J., 21(6), pp. 1227-1250 (2016).

52. Yang, J., Yang, C., Su, M., and Lian, M. "Stress concentration factors test of reinforced concrete-filled tubular Y-joints under in-plane bending", Steel Comp. Struct., An Int. J., 22(1), pp. 203-216 (2016). 
53. Jiang, S., Guo, X., Xiong, Z., Cai, Y., and Zhu, S. "Experimental studies on behavior of tubular T-joints reinforced with grouted sleeve", Steel Comp. Struct., An Int. J., 23(5), pp. 585-596 (2017).

54. Hollaway, L.C. and Cadei, J. "Progress in the technique of upgrading metallic structures with advanced polymer composites", Prog. Struct. Eng. Mat., 4(2), pp. $131-148$ (2002).

55. Zhao, X.L. and Zhang, L. "State of the art review on FRP strengthened steel structures", Eng. Struct., 29(8), pp. 1808-1823 (2007).

56. Zhao, X.L. "FRP strengthened metallic structures", Thin Walled Struct., Special Issue, 47(10), p. 1019 (2009).

57. Jiao, H. and Zhao, X.L. "CFRP strengthened buttwelded very high strength (VHS) circular steel tubes", Thin-Walled Struct., 42(7), pp. 963-978 (2004).

58. Shaat, A. and Fam, A. "Finite element analysis of slender HSS columns strengthened with high modulus composites", Steel Comp. Struct., 7(1), pp. 19-34 (2007).

59. Zhao, X.L., Fernando, D., and Al-Mahaidi, R. "CFRP strengthened RHS subjected to transverse end bearing force", Eng. Struct., 28(11), pp. 1555-1565 (2006).

60. Bambach, M.R., Jama, H.H., and Elchalakani, M. "Axial capacity and design of thin walled steel SHS strengthened with CFRP", Thin-Walled Struct., 47(10), pp. 1112-1121 (2009).

61. Wang, X.G., Bloch, J.A., and Cesari, D. "Axial crushing of tubes made of multi-materials", Proceedings of the 4 th International MECAMAT Seminar on Mechanics and Mechanisms of Damage in Composites and Multi-materials, St. Etienne, France, London, Mechanical Engineering Publications Ltd., pp. 351360 (1991).

62. Nishino, T. and Furukawa, T. "Strength deformation capacities of circular hollow section steel member reinforced with carbon fiber", Proceedings of the 7th Pacific Structural Steel Conference, Long Beach, California, USA, American Institute of Steel Construction (2004).

63. Teng, J.G. and Hu, Y.M. "Behaviour of FRP-jacketed circular steel tubes and cylindrical shells under axial compression", Constr. Build. Mat., 21(4), pp. 827-838 (2007).

64. Alemdar, F., Matamoros, A., Bennett, C., BarrettGonzalez, R., and Rolfe, S.T. "Use of CFRP Overlays to strengthen welded connections under fatigue loading", J. Bridge Eng., 17(3), pp. 420-431 (2012).

65. Lesani, M., Bahaari, M.R., and Shokrieh, M.M. "Numerical investigation of FRP-strengthened tubular Tjoints under axial compressive loads", Comp. Struct., 100, pp. 71-78 (2013).
66. Lesani, M., Bahaari, M.R., and Shokrieh, M.M. "Experimental investigation of FRP-strengthened tubular T-joints under axial compressive loads", Constr. Build. Mat., 53, pp. 243-252 (2014).

67. Lesani, M., Bahaari, M.R., and Shokrieh, M.M. "FRP wrapping for the rehabilitation of Circular Hollow Section (CHS) tubular steel connections", Thin-Walled Struct., 90, pp. 216-234 (2015).

68. ABAQUS/CAE (2014), Standard User's Manual, Version 6.14-1 (2014).

69. AWS D 1.1:2010 (22nd Edition), Structural Welding Code, American Welding Society, Miami FL, USA (2010).

70. Lee, M.M.K. "Estimation of stress concentrations in single-sided welds in offshore tubular joints", Int. J. Fatigue, 21, pp. 895-908 (1999).

71. Chiew, S.P., Soh, C.K., Fung, T.C., and Soh, A.K. "Numerical study of multi-planar tubular DX-joints subject to axial loads", Comput. Struct., 72, pp. 746761 (1999).

72. Lie, S.T., Lee, C.K., and Wong, S.M. "Modeling and mesh generation of weld profile in tubular Y-joint", $J$. Constr. Steel Res., 57, pp. 547-567 (2001).

73. Eckold, G., Design and Manufacture of Composite Structures, Woodhead Publishing Series in Composites Science and Engineering (1994).

74. Bank, L.C., Composites for Construction: Structural Design with FRP Materials, John Wiley \& Sons, Inc., (2006).

75. Ganesh, V.K. and Naik, N.K. "Some strength studies on FRP laminates", J. Compos., Struct., 24, pp. 51-58 (2005).

76. Efthymiou, M. "Development of SCF formulae and generalized influence functions for use in fatigue analysis", OTJ 88, Surrey, UK (1988).

77. N'Diaye, A., Hariri, S., Pluvinage, G., and Azari, Z. "Stress concentration factor analysis for notched welded tubular T-joints", Int. J. Fatigue, 29, pp. 15541570 (2007).

78. IIW-XV-E, IIW Docs.XV-1035-99/XIII-1804-99, Recommended Fatigue Design Procedure for Welded Hollow Section Joints, International Institute of Welding Sub-Commission XV-E, International Institute of Welding, France (1999).

\section{Biographies}

Alireza Sadat Hosseini is a $\mathrm{PhD}$ student in Civil Engineering at University of Tehran (UT), Tehran, Iran. He received his MSc degree in Coastal and Offshore Engineering from Tarbiat Modares University (TMU) in 2013 and his BSc degree in Civil Engineering from UT in 2011. His PhD thesis is in the field of Offshore Engineering, strengthening the offshore tubular joints with fiber-reinforced polymers. The other research contributions are in the field of Coastal 
structures and Port Engineering. He has been a coastal Structure designer and contributed to various largescale marine projects in Iran since 2012.

Mohammad Reza Bahaari is a Professor of Civil Engineering at University of Tehran (UT), Tehran, Iran. He received his BSc and MSc degrees from Sharif University of Technology, Tehran, Iran, and his PhD degree from the University of Waterloo, Ontario, Canada, 1994. He has been a faculty member at UT since then. He has been the Editor-in-Chief for Journal of Faculty of Engineering (FoE) from 1997 to 2005 and assigned as the Head of the Marine Engineering group, here in Colleague of Engineering, UT from March 2013 to present. His research contributions are in the fields of "Semi-rigid beam to column bolted connections in steel frames" along with offshore structures, including oil \& gas platforms, subsea pipelines, and wind turbines. He has been a senior executive Advisor to Iranian Offshore Engineering \& Construction Company
(IOEC) for 20 years and has contributed to jacket, topside, and trunk lines construction, both in Persian Gulf and Indian offshore.

Mohammad Lesani is an Assistant Professor of Civil Engineering at Sadra University, Tehran, Iran. He holds a PhD degree in Marine and Offshore structures from University of Tehran. His research interests include rehabilitation, upgrade, and structural strengthening of various marine and offshore structures, FRP application, tubular joints, pipelines and oil \& gas and marine infrastructure. He has been academically active as a thesis supervisor, a consultant, a referee and lecturer, and also a reviewer of research papers for reputable journals. He has been in the offshore industry for more than 16 years and has contributed to various projects in this field including topside and jacket engineering and construction, asset maintenance and repair, structural inspection, and jetty design in national and international companies. 